\title{
Clinical, epidemiological and therapeutic studies on Bovine Papillomatosis in Northern Oases, Egypt in 2008
}

\author{
Fayez Awadalla Salib ${ }^{* 1}$ and Haithm Ali Farghali ${ }^{2}$ \\ 1. Department of Medicine and Infectious Diseases, \\ 2. Department of Surgery, Anaesthesiology and Radiology \\ Faculty of Veterinary Medicine, Cairo University, Egypt. \\ * Corresponding autor email : fayez_vetmed@hotmail.com
}

\begin{abstract}
Bovine papillomatosis is a viral disease of cattle characterized clinically by development of multiple benign tumours termed warts. The diagnosis of bovine papillomatosis was confirmed by clinical and pathological examinations of the warts. The prevalence of bovine papillomatosis in Northern Oases was recorded as $4.86 \%$. The prevalence was higher in the females $(2.99 \%)$ than males $(1.87 \%)$. The prevalence was the highest in cattle less than one year old (2.99\%). The infected cattle were examined visually for detection of external parasites and faecal samples were examined for detection of internal parasites. Infestation with ticks was observed in 10 of the 13 confirmed wart infected animals, while fasciola and parasitic gastroenteritis (PGE) nematode eggs were demonstrated and quantified in 4 and 5 infected bovids respectively. The statistical correlation between the number of warts and Fasciola eggs, and number of parasitic gastroenteritis (PGE) nematode eggs, was 0.6 and 0.89 accordingly. Two therapeutic regimes were evaluated, regimenI and regimen-II. All cattle treated were completely recovered in days post treatment 15 to 115 . We concluded that treatment regimen-I was better than regimen-II when taking into consideration the mean days lapsed for healing and regression of warts of 42 days compared to 83 days for regimen-II.
\end{abstract}

Key words: Cattle, Wart, Epidemiology, Parasite, Therapy, Egypt.

\section{Introduction}

Papillomviruses are small (55 $\mathrm{nm}$ in diameter) non enveloped, icosahedral viruses, containing a double stranded, circular DNA genome about 8000 base pairs long. They are found throughout higher vertebrates, mostly mammals and birds, causing cutaneous and mucosal tumours (William, 2009). Bovine papillomatosis (warts) is a disease caused by host, site and lesion specific papillomaviruses. Bovine papillomavirus (BPV) has six serotypes hitherto (Olson,1990). The disease is usually spread by direct contact with infected animal and is entered to animal skin by cutaneous abrasions. It gains its economic importance through interfering with animal sales and shows, as extensive bovine papillomatosis causes the animal to lose his condition specially when the lesions get infected secondarily with bacteria. Teat warts are also interfering with milking process (Radostitis et al., 2007). These warts may regress spontaneously or occasionally persist, and, in the presence of additional critical genetic or environmental factors, can progress to cancer (Campo,1987). It is thought to be a multistep affair (Koller and Olson, 1972 ; Lancaster and Olson, 1982). Papillomavirus infection developed as a result of the virus exposure to single or multiple lesions of the epithelium of the skin. The transformation and multiplication of papillomavirus infected basal cells, lead to wart formation, the most warts are benign and do not proliferate indefinitely causing cancer ( Shah and Howley, 1996).

The immune-suppressive factors play a role in progression of bovine papillomatosis as mentioned by Radostitis et al. (2007), including internal and external parasites.

Different methods have been used to treat bovine papillomas. formalinized inactivated vaccine of bovine warts proved to be effective treatment and good prophylaxis against bovine papillomatosis (Barthold et al.,1976; Hunt, 1984; Lesnik et al.,1999; Suveges and Schmidt, 2003). Intra-lesional immunotherapy by Corynebacterium parvum has also been reported by Hall et al.(1994).

In this study, bovine papillomatosis was suspected in cattle in Northern Oases, $6^{\text {th }}$ October governorate, Egypt, the developed skin lesions were recorded along with age, sex of affected cattle, number and site of lesions, presence of external and internal parasites. The diagnosis was confirmed by pathological examinations. Therapeutic trials were done for the treatment of affected cattle with two different regimes. 
Table-1.: Epidemiological data of papillomavirus infected cattle

\begin{tabular}{lcccc}
\hline Papillomatosis & \multicolumn{2}{c}{ Infected cattle } & Non infected cattle \\
\cline { 2 - 5 } & Number & Prevalence (\%) & Number \\
\hline Male cattle & 5 & 1.87 & 108 & 146 \\
Female cattle & 8 & 2.99 & 76 & 113 \\
Cattle less than 1 year old & 8 & 2.99 & 57 & 84 \\
Cattle less than 2 years old & 3 & 1.12 & 63 & 58 \\
Cattle from 2 to 5 years old & 1 & 0.37 & 58 & 54 \\
Cattle above 5 years old & 1 & 0.37 & 254 & 267 \\
Total & $13^{*}$ & 4.86 & & 267 \\
\hline
\end{tabular}

The aim of this study was to describe the cases of bovine papillomatosis in Northern Oases, with special focus on the diagnosis, predisposing parasitic infections and comparison of two treatment regimens instituted.

\section{Material and methods}

I-Clinical and epidemiological examination: In northern oases, October $6^{\text {th }}$ governorate, Egypt, 267 cattle were examined for presence of warts. General clinical examinations were carried out and all visible skin lesions were described according to site and numbers of warts present, and recorded (in a specially prepared questionnaire), together with the age and sex of the infected cattle. Suspected infected cattle were visually examined for detection of external parasites and coprologically inspected for internal parasites and their eggs. The recorded data were statistically analyzed by SPSS (Version 16) program .

II-Parasitic examination: Ticks found on the cattle skin were identified macroscopically. Internal parasites were diagnosed by faecal examination. Faecal matter were collected by back racking from papillomatosis infected cattle and were examined by both concentration flotation and concentration sedimentation techniques according to Denham and Suswillo (1995). The Mc master technique for counting eggs of parasitic gastroenteritis (PGE) nematodes was also done (Dunn, 1969; Georgi, 1980; Whitlock, 1948), number of eggs per gram faeces was calculated by multiply mean number of actually counted eggs per Mac master slide to 100 . The Fasciola eggs were counted by using method of Happich and Boray (1969), the actually counted Fasciola eggs were considered eggs per gram faeces.

III-Pathological examination: Histopathological and negative staining examinations of warts were done. Histopathological sections were carried out by fixing of excised warts of living animals in $10 \%$ neutral buffered formalin solution. The fixed specimens were trimmed, washed and dehydrated in ascending grades of alcohol, cleaned in xylene, embedded in paraffin then sectioned (4-6 micron) and stained with hematoxyline and eosin according to Bancroft et. al., (1996).

Tissue samples were prepared for electron microscopy by the negative staining technique (Nenad et al., 2005), the pelleted wart tissue containing viral particles were resuspended in distilled water and a drop of viral suspension was placed on a Petri dish. A Formvar-coated electron microscopy (EM) grid was placed Formvar side down on top of the virus drop for approximately 1-3 minutes. The grid was removed, blotted with filter paper and placed onto a drop of $2.0 \%$ phosphotungstic acid (PTA), $\mathrm{pH} 7.0$, for one minute. The excess PTA was removed, and the EM grid was ready for viewing in the electron microscope unite of VACSERA company.

I V-Treatment: The external or internal parasites infested cases were treated by injection of Ivermectin and oral dosing of triclabendazole. The papillomatosis infected cattle were treated with two different regimes and they were evaluated.

a-Anti-parasitic drugs were given for cattle proved to be infected,

Ivermectin (Iveen®, ADWIA company, Egypt) was injected subcutaneous at a dose rate of $200 \mathrm{mcg} / \mathrm{kg}$ bodyweight $(1 \mathrm{ml} / 50 \mathrm{~kg}$ bodyweight $)$ and triclabendazole was given orally at dose rate of 12 $\mathrm{mg} / \mathrm{kg}$ bodyweight(Fascinex ${ }^{\circledR}$, Novartis co.)

b- Surgical treatment of warts

i-Sedation : Cattle was sedated with xylaject ( $2 \%$ solution (xylazine, ADWIA company, Egypt) at a dose rate of $0.1 \mathrm{mg}$ per $1 \mathrm{~kg}$ bodyweight by intramuscular injection. The animal was well restrained and tied before surgical excision of warts by one of the following regimes:

ii-Regime I: Excision of large sized warts was performed by sharp scalpel, and hemorrhage was controlled using electrocautery. Seven papilloma infected cattle were treated by regime-I.

iii-Regime II: Curetting to remove overgrowth of warts by a scalpel till blood oozes to allow the reintroduce of virus into blood (Autogenous 
Table-2.: Site and number of warts and the accompanied parasitic infestations.

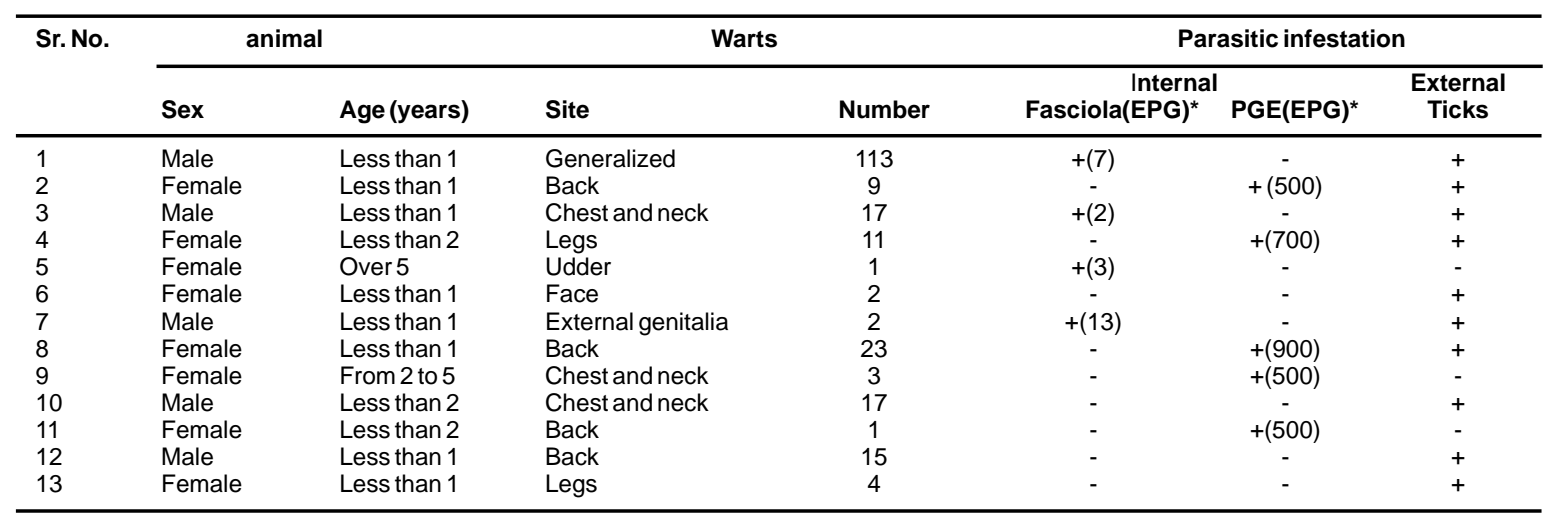

vaccine).Trichloro-acetic acid (El-Gomhuria co., Egypt) was applied topically post-curetting to kill and remove the rest warts cells. Levamizole (ADWIA company, Egypt) was injected subcutaneous at a dose rate of $1 \mathrm{ml} / 10 \mathrm{~kg}$ bodyweight as immune stimulant (Cam et al.,2007). Six papilloma infected cattle were treated by regime-II.

The bovines in all treatment regimens were injected with Multivitamin ${ }^{\circledR}$ at dose rate of $1 \mathrm{ml} / 10$ $\mathrm{kg}$ bodyweight by intramuscular injection (NorBrook company,Egypt). A Betadine ${ }^{\circledR}$ spray (Bovidone iodine skin solution, Nile company for pharamaceuticals and chemical industries) was applied topically on the skin wounds to prevent problems with secondary bacterial infection and myiasis.

V-Statistic analysis: Data were analysed using SPSS (Version 16) program.

\section{Results}

Clinical findings, epidemiological data, parasitic infestations, pathological findings, results of treatment including anti-parasitics and surgical treatment of warts using regime- 1 or regime- 2 and results of statistic analysis were illustrated as in tables$1,2,3,4$ and 5 and figures 1,2 and 3 .

I-Clinical examination: of 267clinically examined cattle, only thirteen cases of bovine papillomatosis were found. The body temperature of infected cattle were normal $\left(38-38.5^{\circ} \mathrm{C}\right)$. The appetite of infected cattle was normal. The body condition of heavily infected cattle was poor (Radostitis et al., 2007). The site of warts and the warts count per animal were recorded as shown in table 2. Warts were observed in the generalized form in only one cattle where warts distributed on both sides of the body; large sized warts were concentrated in the right side. One wart was 13 $\mathrm{cm}$ in width and $20 \mathrm{~cm}$ in length, and extended from the base of the ear to reach edge of the mandible. It was irregular, rough and sessile, with hyperkeratosis. The variable sized warts were observed in other 12 bovines at different sites of the body skin including Back , Chest and neck, Legs, Udder, Face and External genitalia.

I I-Epidemiology: The prevalence of bovine papillomatosis in Northern Oases in 2008, was recorded as $4.86 \%$. The prevalence was higher in the females $(2.99 \%)$ than males $(1.87 \%)$. The prevalence was the highest in cattle less than one year old $(2.99 \%)$. The number and percentage of papillomatosis lesions regarding site were recorded as the generalized (1, $7.69 \%)$, Back (4, 30.76\%), Chest and neck (3, $23.07 \%)$, legs $(2,15.38)$, udder $(1,7.69)$, face $(1,7.69)$ and external genitalia $(1,7.69 \%)$.

Spearman rank correlation between number of warts and number of Fasciola eggs per gram faeces was 0.6 while between number of warts and number of PGE eggs per gram faeces was 0.89 .

III-Parasitic burden evaluation: Among the 13 BPV infected cattle, 10 were infested with ticks $(76.92 \%)$, and $4(30.76 \%)$ and $5(38.46 \%)$ had fasciola and PGE helminths burdens respectively. I V-Pathology: Histopathologically, there was marked parakeratotic hyperkeratosis with long, thick, hair-like cornified surface projections and papillate epidermal hyperplasia, with patchy areas of erosion, ulceration, and neutrophil infiltration. The underlying dermal papillae had a moderate infiltration of neutrophils, eosinophils, and fewer lymphocytes (Prince Edward, 1994).

EM images of the wart suspensions indicated a small non enveloped virus with an approximate diameter of $60 \mathrm{~nm}$, composed of capsomeres arranged in icosahedral symmetry. The virus description matched that of BPV as previously reported by Shah and Howley(1996).

V-Treatment: All cattle treated were completely 
Table-3.: Comparison of the counts of warts, PGE eggs and fasciola eggs.

\begin{tabular}{lccccccc}
\hline Counts & Animals & Range & Minimum & Maximum & Mean & Std. Error & Std. Deviation \\
\hline Warts & 13 & 112 & 1 & 113 & 16.77 & 8.275 & 29.836 \\
PGE eggs & 5 & 400 & 500 & 900 & 620.00 & 80.000 & 178.885 \\
Fasciola eggs & 4 & 11 & 2 & 13 & 6.25 & 2.496 & 4.992 \\
\hline
\end{tabular}

recovered from 15 to 115 days post-treatment (DPT). Treatment regime I was superior to regimen II when considering the time interval between treatment and healing and regression of warts. Mean time taken for healing for regimen I and II were 42 and 83 days accordingly.

\section{Discussion}

Although bovine papillomatosis is a selflimiting disease, the warts in our study have long time to regress and animal to recover. The diagnosis of bovine papillomatosis was confirmed by presence of variable sized cutaneous warts and histopathology. Economical impact of the disease is clearly observed in loss of animal condition, secondary bacterial infection, skin myiasis, interfering lactation process and lastly reduce animal price and sometimes hinders the sale.

Of 13 bovine papillomatosis infected cattle, 5 male and 8 female cattle, were infected. The role of sex in the infection may return to the female cattle usually under stress factors such as gestation, lactation and progression in age. On other hand, male cattle are usually directed to fattening and meat production and are mostly slaughtered at age of 2 years or less.

Of 13 infected cattle, 8 infected cattle were less 1 year of age , 3 infected cattle were less 2 years of age , 2 infected cattle were over 2 years of age. It clear the young ages are more susceptible to the infection than the adult as described by Otter and Leonard (2003), they recorded an outbreak of fibropapillomas in calves. It is thought to be due to ill-developed immune system, alkaline $\mathrm{pH}$ of the skin of young ages, most of these animals have been weaned, lost their maternally derived antibodies and are in the process of building their own immunities while being challenged by many pathogens; that may facilitate virus infection and also young ages are more susceptible to parasitic infestation and exposure to stress factors.

A high tick infestation rate $(76.92 \%)$ was observed among the infected animals. It is believed that ticks have two inducing roles for bovine papillomatosis viz 1) They pierce the skin and create entry points where viruses enter the cutaneous tissue, infect basal keratinocytes and replicate their genomic materials in the differentiating spinous and granular layers of the epidermis, and cause development of excessively grown warts (Radostitis et al., 2007).

2) The tick sucks a large volume of host blood where it inserts its hypostome into the skin and secrete a cement from the salivary glands to secure the hypostome in place. They damage the skin barrier while feeding on host blood; secrete saliva that prevent the clotting of blood and has also immune suppressive effects. Jitka et al., (2004) confirmed that Th2 cytokines; IL- 6 and IL- 10 were down regulated by salivary gland extracts of Ixodes ricinus. The immune suppression enhance papilloma virus infection (Lesnik et al., 1999; Brady et al., 1999; Koski and Scott,2003)

The immune suppression enhance papilloma virus infection (Lesnik et al., 1999; Brady et al., 1999;

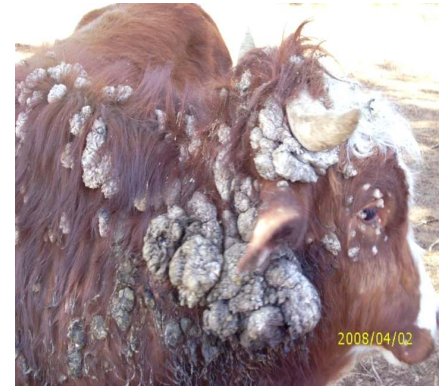

Figure-1: a calf showing multiple large sized warts distributed all over the skin before treatment (right side).

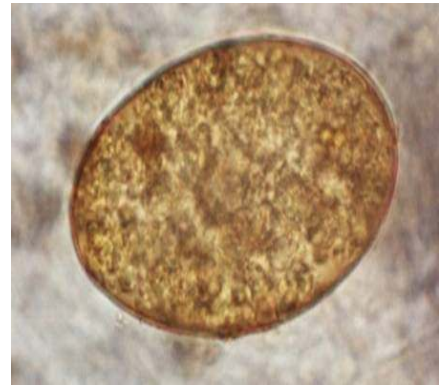

Figure-2: Fasciola egg (X100).

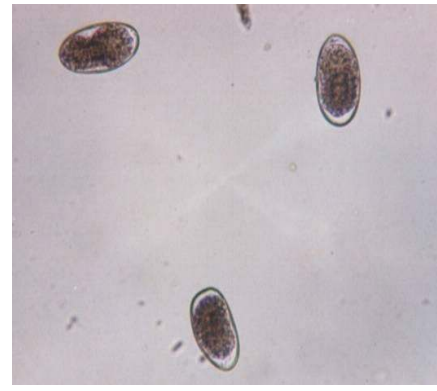

Figure-3: Parasitic gastroenteritis nematodes eggs ( $\mathrm{X} 40$ ). 
Table-4.: Comparison of the counts of warts, PGE eggs and fasciola eggs.

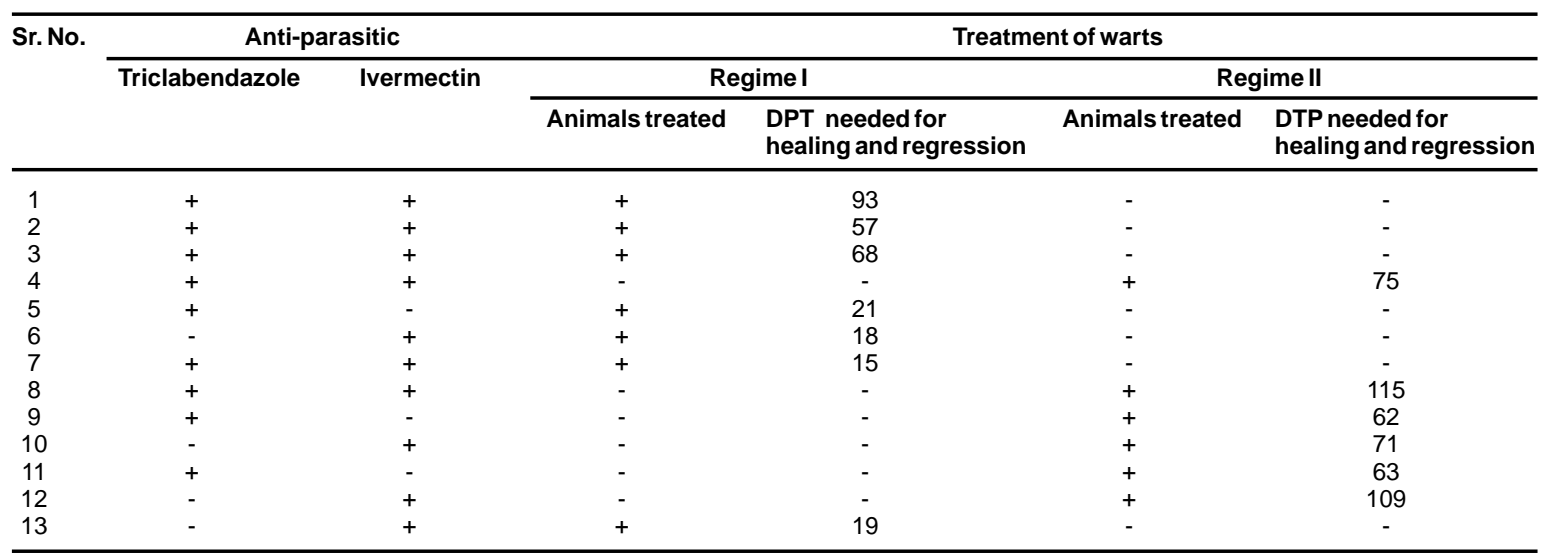

Koski and Scott, 2003). Both PGE nematodes and Fascioliasis play a role as immune suppressive so that they facilitate virus infection. 5 out 13 papillomatosis infected cattle were suffering parasitic gastroenteritis PGE nematodes that have an immune suppressive effect as recorded by (Koski and Scott, 2003), they stated that deficiencies of iron, molybdenum, copper, and zinc, had been associated with higher worm burdens consequently affected immune response. 4 out of 13 papillomatosis infected cattle were suffering from Fasciola that have an immune suppressive effect as reported by Brady et al.(1999), they mentioned that Th1 response to B. pertussis antigens was markedly suppressed and the bacterial infection was exacerbated following infection with $F$. hepatica. Five and 4 animals with papillomatosis in this study were infested with PGE nematodes and Fasciola helminthes respectively (Table-2). The immune suppressive nature of both parasites was clear where the correlation between number of warts and that of fasciola eggs per gram faeces was 0.6 and the correlation between number of warts and that of PGE eggs per gram faeces was 0.89 .

The two therapeutic regimens, regime-I and regime-II, were evaluated for treatment of bovine papillomatosis. In regime-I, The surgical excision of large warts were done using a scalpel and bleeding was controlled by electrocautery. The metastatic virus particles may circulate in the blood and act as autovaccine. The second regime including curetting the warts aimed to reintroduce the virus to circulation which was considered as autogenous vaccination, topical application of trichloro-acetic acid was done and the injection of immune stimulant (Levamizole) were used for treatment of animals. Warts regression and time elapsed until recovery of the infected animals were used to measure efficiency. The regression of warts and healing were observed 15-115 days post treatment. Regime-I was superior to regime-II considering the mean of 42 days required for regression of warts and healing compared to the 83 days for regime-II.

Treatment of bovine papillomatosis with autogenous vaccine produced by grinding and suspending wart indicate variable results. In regime-I, the blood circulating metastatic virus particles stimulate the immune system. In regime-II, curetting of warts aimed to reintroduce papilloma virus into blood (autogenous vaccination) and application of trichloroacetic acid aimed to kill warts cells, papilloma virus, skin bacteria and stop light bleeding. The rate of success in both regimes I and II was $100 \%$ that is agree with that was reported by (Suveges and Schmidt, 2003) where autogenous vaccine yielded 93.5\% success rates 105 days post vaccination, with no differences observed in the type of vaccine utilized. Our results agree with previous investigations where it was proven that autogenous vaccines prepared from sterile homogenized warts and administered twice prevented new cases and treated sick animals (Suveges and Schmidt, 2003), and disagree with Smith's report (1990) recorded that treatment with autogenous wart vaccine was ineffective. Commercial vaccines for bovine papillomatosis are not effective in promoting regression of existing warts or preventing malignant progression, although they might be capable of preventing the development of new lesions if they contain the same strain as the outbreak virus (Smith,1990; Campo, 1991; Scott and Anderson, 1992).

The role of Levamizole as non specific immune stimulant is very clear in many infections as reported e 
Table-5.: Comparison of Regime-I and I I for treatment of warts.

\begin{tabular}{lcccccc}
\hline Treatment & Number of treated cattle & \multicolumn{4}{c}{ Days needed for healing and regression of warts } \\
\cline { 3 - 7 } & & Minimum & Maximum & Sum & Mean & Std.Deviation \\
\hline Regime-I & 7 & 15 & 93 & 291 & 41.57 & 31.026 \\
Regime-II & 6 & 62 & 115 & 495 & 82.50 & 23.441 \\
\hline
\end{tabular}

by Cam et al.(2007), they evaluated it for treatment of bovine cutaneous papillomatosis and Amery and Butterworth (1983), they found that Levamizole had good effect as an immunomodulator for blood disorders, renal failure, vasculitis and photosensitivity, inspite of that the immune stimulating effect of levamizole against bovine papillomatosis was non-obvious where the levamizole may promote the general immune response but it could not help in eliminating the warts in rapid manner. That was disagree with the past studies of the role of non specific immunomodulator (parapoxvirus) against bovine papillomatosis. As shown in several in vivo studies, the stimulation of endogenous, non-antigen related defense mechanisms by parapoxvirus-based immunomodulators opens up new possibilities for the control and treatment of infectious diseases in domestic animals (Strube et al., 1989; Ziebell et al.,1997; Castrucci et al., 1998; Kyriakis et al., 1998; Glitz, 2002). The Inactivated parapox ovis viruses had a complex genetic structure and thereby they were considered as non-specific strong immunomodulator, which induced host immune reaction. There was evidence that such immune reactions resulted in more than elimination of the virus (Fachinger et al., 2000).

The efficacy of bovine papillomatosis treatment with the autogenous vaccine and a parammunity inducer was observed useful for the earlier regression of papillomas in the early stage of disease (growing stage of warts). It was believed that a parammunity inducer also showed a beneficial effect in additional treatment of bovine papillomatosis (Nenad et al., 2005). Nonetheless the immune stimulating effect of levamizole against bovine papillomatosis was not obvious in this study, where warts from animals which received it in their treatment regimen did not regress rapidly. We conclude that surgical excision of warts is a better treatment option for bovine papillomatosis than curetting, autogenous vaccine and administration of levamisole.

\section{References}

1. Amery, W.K., Butterworth, B.S., (1983). The dosage regimen in cancer: is it related to efficacy and safety? Int. $J$. Immunopharmacol. 5, 1-9.

2. Bancroft, J.D, Stevans, A., Turner, D.R., (1996). Theory and practice of histological techniques. $4^{\text {th }}$ Ed. Churchill
Livinigstone, Edinburgh, London, Melbourne, New York.

3. Barthold, S.W, Olson, C., Larson, L.,(1976). Precipitin response of cattle to commercial wart vaccine. Am. J. Vet. Res. 37, 449-451.

4. Brady,M.T., O`Neill,S.M., Dalton,J.P., Mills, K.H.G. (1999). Fasciola hepatica Suppresses a Protective Th1 Response against Bordetella pertussis. Infection and Immunity, 67(10),5372-5378.

5. Cam, Y., Kibar, M., Atasever, A., Atalay, O., Beyaz, L. (2007). Efficacy of levamisole and Tarantula cubensis venom for the treatment of bovine cutaneous papillomatosis.Vet. Rec. 7, 160(14),486-488.

6. Campo, M.S., (1987). Papillomas and cancer in cattle. Cancer Surv. 6, 39-54.

7. Campo, M.S., (1991). Vaccination against papillomavirus. Cancer Cells 3, 421-426.

8. Castrucci, G., Frigeri, F., Osburn, I. B., Ferrari, M., Barreca, F., Salvatori, D., (1998). Further investigation on the efficacy of a non-specific defence inducer evaluated incalves exposed to infectious bovine rhinotracheitis virus. Comp. Immunol. Microbiol. Infect. Dis. 21, 155-163.

9. Denham, D.A., Suswillo, R.R.,(1995). Diagnosis of intestinal helminth infections. In Gillespie SH, Hawkey PM (eds), Medical Parasitology: A Practical Approach. IRL/Oxford University Press: Oxford, 253-265.

10. Dunn, A.M. (1969). Veterinary Helminthology. William Heinemann Medical Books Ltd. London. pp. 179, 276-278.

11. Fachinger,V., Schlapp, T., Strube, W., Schimeer,N., Saalmuller, A., (2000). Poxvirus-induced immunostimulating effects on porcine leukocytes. J. Virol. 74, 7943-7951.

12. Georgi, J.R., (1980). Parasitology for Veterinarians (3rd Ed.), WB Saunders Company, Philadelphia, pp. 179

13. Glitz, F. (2002). Effects and indications regarding use of immunomodulator $\left(\right.$ Baypamun $\left.^{\circledR}\right)$ in small animals and rabbits. Kleintierpraxis 47, 427-431.

14. Hall,H., Teuscher, C. , Urie, P., Boden, B., Robison, R., (1994). Induced regression of bovine papillomas by intralesional immunotherapy. Therap. Immunol. 1, 319-324.

15. Happich, F.A., Boray, J.C., (1969). Quantitative diagnosis of chronic fasciolosis: 1.Comparative studies on quantitative faecal examination for chronic Fasciolahepatica infestation in sheep. Australian Veterinary Journal 45,326-328.

16. Hunt, E., (1984). Fibropapillomatosis and papillomatosis Vet. Clin. North Am. Large Anim. Pract. 6, 163-167.

17. Jitka, P., Jan, K., Jirí, S., (2004). Effect of tick salivary gland extract on the cytokine production by mouse epidermal cells. Folia Parasitologica 51, 367-372.

18. Koller, L. D., Olson, C., (1972). A hempted transmission of warts from man, cattle, and horses and of deer fibroma, to selected hosts. J. Invest. Dermatol. 858, 366.

19. Koski, K.G., Scott, M.E., (2003). Gastrointestinal Nematodes, Trace Elements, and Immunity. The Journal of Trace Elements in Experimental Medicine 16, 237-251.

20. Kyriakis, S. C., Tzika, E. D., Lyras, N. D., Tsinas, K., Saoulidis, K., Sarris, K., (1998). Effect of an inactivated Parapoxvirus based immunomodulator (Baypamun) on post weaning diarrhoea syndrome and wasting pig syndrome of 
piglets. Res. Vet. Sci. 64, 187-190.

21. Lancaster, W. D., Olson, C.,(1982). Animal papillomaviruses. Microbiol. Rev. 46, 191-207.

22. Lesnik, F., Bires, J., Suli, J., Posivak, J., Mattova, J., Svrcek, S., Sevcikova, Z., Kvokacka, V., Gaspar, V., Levkut, M., Buleca, J., (1999). Autovaccination and metabolicprofiles at bovine papillomatosis. Slovak Vet. J. 24, 290-294.

23. Nenad, T., Željko, Ž., Vilim, S., Snježana, K., Tomislav, B., Mario, K., Stipica, C., Ljubo, B., Zoran, M., (2005). Severe bovine papillomatosis: detection of bovine papillomavirus in tumour tissue and efficacy of treatment using autogenous vaccine and parammunity inducer. Veterinarski Arhiv 75(5), 391-397.

24. Olson, C., (1990). Papillomaviruses. In: Virus Infections of Ruminants (Dinter, Z., B. Morein, Eds.).

25. Otter A, Leonard D., (2003). Fibropapillomatosis outbreak in calves. Vet Rec. 153(18),570-571.

26. Prince Edward, I.,(1994). Papillomatous digital dermatitis in a Canadian dairy herd. Can. Vet. J. Volume 35.

27. Radostitis,O.M., Gay,C.C., Hinchcliff, K.W., Constable, P.D.(2007) textbook of Veterinary Medicine, $10^{\text {th }}$ edition, 2008 print.; printed by El-sevier, Spain, ISBN: 978-0-70202777-2, pp.1421-1423.

28. Scot, D. W., Anderson, W. I., (1992). Bovine cutaneous neoplasms: literature review and retrospective analysis of 62 cases (1978-1990). Comp. Cont. Educ. 14, 1405-1416.
29. Smith, B. P., (1990). Papillomatosis (warts, fibropapillomas). In: Large Animal Internal Medicine (Smith, B. P., Ed.). The C. V. Mosby Company, Missouri.

30. Strube, W., Kretzdorn , D., Grunmach , J. , Bergle , R. D., Thein , P., (1989). The effectiveness of the parammunity inducer Baypamun (PIND-ORF) for the prevention and methaphylaxis of an experimental infection with the infectious bovine rhinotracheitis virus in cattle. Tierärztl. Praxis 17, 267-272.

31. Suveges, T., Schmidt, J., (2003). Newer data on the occurrence in Hungary of losses caused by and ways of control of bovine papillomatosis. Magy. Allatorvosok 83 .

32. Shah, K.V., Howley, P.M.,(1996). 'Papillomaviruses' in Fields Virology (3rd edition) (Fields BN, Knipe DM, Howley PM, et al., eds), Lippincott-Raven Publishers, Philadelphia, pp. 2077-2101.

33. Whitlock, H.V.,(1948). Some modifications of the McMaster helminth egg counting technique and apparatus. J. Counc. Sci. Ind. Res.21,177-180.

34. William, B., (2009). Cited in the textbook of vaccines for biodefense and emerging and neglected diseases.2009 edition, printed by Elsevier Inc.

35. Ziebell, K. L, et.al.(1997). The use of Baypamun Nin crowding associated infectious respiratory disease: efficacy of Baypamun N (freeze dried product) in 4-10 month old horses. Zbl. Veterinärmedizin 44, 529-536. 